laboratory experiments. In particular, the photosynthetic potential in primary production budgets of the underlying sediments of shallow estuary sites is demonstrated. The potential emission of atmospheric trace gases contributing to the greenhouse effect (e.g. $\mathrm{N}_{2} \mathrm{O}$, $\mathrm{CH}_{4}$ ) and the seasonal fluxes of iron and manganese associated to the process of benthic microbial degradation of organic matter are quantified. The inorganic nutrients release at the sediment water interface, the role of sediment resuspension on this release and the impact of benthic remineralization in sustaining the water column primary production are investigated emphasizing the role of eutrophication on these last processes. Section 4 contains two papers on the sediments geochemistry. One discusses the role of the saltmarshes vegetation in the sediment chemistry (in the Tagus estuary, Portugal) and, in particular, it investigates the influence of the release of oxidants by the plant roots on the benthic remineralization process and on the immobilization of metals such as zinc and lead. The other paper analyses the composition of historically deposits with the aim of reconstructing the paleoenvironmental events in the eastern Yellow Sea. The last section contains six papers on sea level rise, land reclamation and resource management from Cameroon, China and the Waden Sea. Time series data, satellite observations and a few modelling results are analyzed in view of assessing the impact of sea level rise and human activities (e.g. urbanization, industrial development, land reclamation) on the functioning of the aquatic ecosystem (e.g. biodiversity, sediment composition) and on the evolution and hydrography of river deltas, tidal flats and salt marshes as well as to compare this impact to this normally associated with natural geological processes.

The papers presented in this book are all of high quality level, clearly written and organized including high-quality illustrations and a complete uniform bibliography. My criticism to this otherwise very good book is that the aspect "resource management" of the last section is not so innovative and complete as we could have hoped. The subject is treated in a very general way, the results presented are mainly derived from the interpretation of existing data and the associated recommendations are very general and are not obtained based on a thorough understanding of the dynamics of the studied area and of its specificities. This understanding can be acquired using integrated approach combining mathematical modelling and data analysis for scenarios testing and management purposes.

I recommend this survey of case studies that provide an up-to-date review of the state of the art in the dynamics of muddy coastal waters to specialists in this area, as well as to those with a more general interest in the physical and biogeochemical functioning of muddy coastal areas and in their protection.

Marilaure Grégoire F.N.R.S. Research Associate, Geophysics Department, University of Liege, G.H.E.R., Sart Tilman B5, 4000 Liege, Belgium

E-mail address: mgregoire@ulg.ac.be Tel.: +32-4-366-33-54; fax: +32-4-366-23-55

PII: S0924-7963(02)00180-X

\section{Coastal and estuarine fine sediment processes}

Edited by W.H. McAnally and A.J. Metha, Elsevier Science, ISBN 0-444-50463-X, 540 pages. Price: EUR 179.24, USD 194.50. Available: in Europe: Elsevier Amsterdam, P.O. Box 211, 1000 AE Amsterdam, The Netherlands, in USA/Canada: Elsevier Science, P.O. Box 945, Madison Square Station, New York, NY 10160-0757, U.S.A.

Muddy coastlines are important habitats and can provide natural shoreline protection due to their ability to attenuate wave energy. Cohesive sediment transport processes in muddy coastal and estuarine areas have important effects on the economy (e.g. tourism, fisheries, harbours) and the environment (mudflats are the basis of ecologically valuable, but vulnerable coastal wetlands). Therefore, cohesive sediment transport is an important interdisciplinary research field with a wide range of applications. For instance, navigation in channels and harbours is often limited by fine sediment transport. More recently, the role of fine sediment in capturing and transporting contaminants has become a major question than can 
no longer be ignored. These examples highlight the usefulness of understanding the erosion and settling of cohesive sediments.

The new book from Elsevier's "Proceedings in Marine Science" series, contains papers presented at the fifth international conference on Nearshore and Estuarine Cohesive Sediment Processes, INTERCOH'98, held in Seoul, Korea, 26-30 May, 1998. This conference brought together the expertise and research efforts of scientists from more than 15 different countries in the fields of fluid mechanics, geography, geology, oceanography, hydraulics, coastal and construction engineering, environmental protection and atmospheric science. The book presents 31 papers that examine the spectrum of fine sediment transport related science and engineering, including the basics and applications of flocculation, settling, deposition and erosion, advanced numerical models used in engineering practice and applications to mud flats and harbour siltation.

An introductory paper provides an up-to-date review of the state of the art in cohesive sediment transport research in Europe with a particular emphasis on the increasing use of detailed integrated numerical models as virtual laboratories. The erosion process is deeply investigated with about 13 papers on the subject. In particular, the floc erosion process of cohesive sediment (i.e., the occurrence of finite erosion for zero excess shear stress) is investigated using laboratory experiments, the erosion of mixtures of fine-grained sediments and of mud with a high water content is examined and a mathematical formulation of their critical shear stress is established. The efficiency of mud scour by wave breaking is studied and parameterised, its impact on the rheological properties of mud sediment is emphasized and the onset of the liquefaction process and fluid mud generation is modelled as a function of fluid mud properties. Papers (3) dealing with the study of the influence of various physical and biological factors such as tidal and non-tidal circulation, temperature, salinity stratification, biology (benthic micro-organisms), turbulence level, bottom topography on the sediment erodibility and deposition in river estuaries are also included.

About eight papers deal with the aggregation/ flocculation and settling/deposition processes. Papers on the subject include a thorough description of the interaction, aggregation/flocculation and settling of fine-grained sediments as well as an estimation of the impact of the biology on these processes. In particular, the role of the faecal pellets formed by aggregation of the surface bed material in enhancing the overall settling velocity of the suspended material is studied. A fractal analysis is presented as a tool for reconstructing the random component of the long-term depositional process in high-energy environments.

A lot of papers (about seven) deal with the modelling of sediment transport and its application in coastal engineering and environment protection. Most of the models presented consist of $3 \mathrm{D}$ or $2 \mathrm{D}$ (depth averaged) hydrodynamical models of tidal processes coupled with a 2D sediment transport model including usually simple formulations of several sedimentary processes such as flocculation, consolidation, erosion and deposition and assuming a sharp interface (lutocline) between the mud layer and the water above, with semi-empirical exchange formulations between them for entrainment and settling. On the other hand, a 1D model of sediment transport considering the water/sediment mixture as a continuous fluid is presented. Papers have stressed the importance of taking into account, in the lower boundary layer of muddy river estuaries, the effect of suspended sediment in enhancing fluid viscosity and in the damping of turbulence and of using mathematical models distinguishing multiple grain classes if one wants to obtain an improved representation of the erosion and mainly deposition processes of fine-grained sediments. A method for continuous monitoring of the surface suspended sediment concentration using ferry boats has been found very helpful when used conjointly with satellite remote sensing (e.g. SeaWiFS, NOAA) in collecting information for obtaining the initial and boundary conditions of such sediment transport models. Several applications of sediment transport models are described with, for instance, the prediction of the propagation of contaminant loads transported on the sediments and the assessment of the tidal hydrodynamics and sediment release on the morphology of intertidal mudflats in view of predicting the effects of climate change and engineering works. 
Finally, two papers study the process of siltation at the entrance of ports and propose solutions to reduce the siltation rates.

Thanks to the peer reviewing of the papers and to a very clear style, this book of proceedings reaches a very high quality. I recommend this survey of case studies that explore the dynamics of suspended sediment to specialists in this area, as well as to those with a more general interest in coastal engineering and environment protection.
Marilaure Grégoire F.N.R.S. Research Associate, Geophysics Department, G.H.E.R., University of Liege, Sart Tilman B5, 4000 Liege, Belgium E-mail address: mgregoire@ulg.ac.be Tel.: +32-4-366-33-54; fax: +32-4-366-23-55

PII: S 0924-7963(02)00181-1 